\title{
Do Stock Prices in Turkey Reflect Fundamental Information? A Firm-level Analysis
}

\author{
M. Arifur Rahman ${ }^{1}$, M. Shibley Sadique ${ }^{2} \&$ Shah Saeed Hassan Chowdhury ${ }^{3}$ \\ ${ }^{1}$ Faculty of Business, Economics \& Policy Studies, Universiti Brunei Darussalam, Brunei Darussalam \\ ${ }^{2}$ Department Finance and Banking, University of Rajshahi, Bangladesh \\ ${ }^{3}$ Department of Accounting and Finance, Prince Mohammad Bin Fahd University, Saudi Arabia \\ Correspondence: M. Arifur Rahman, Faculty of Business, Economics \& Policy Studies, Universiti Brunei \\ Darussalam, Gadong BE1410, Brunei Darussalam. E-mail: arifur.rahman@ubd.edu.bn
}

Received: September 6, 2012

Accepted: October 20, $2012 \quad$ Online Published: October 31, 2012

doi:10.5539/ijef.v4n12p137

URL: http://dx.doi.org/10.5539/ijef.v4n12p137

\begin{abstract}
This paper investigates the correspondence between stock prices and firm fundamentals in Turkey. In pursuing our objective, we explore the relationship between firm-specific variation in stock returns and fundamentals in the context of a simple present value framework. We overcome the typical insufficiency of the spans of time-series accounting data in emerging market research, and the consequent loss of statistical testing power, by adopting a firm-level micro panel data approach. After properly accounting for unobserved heterogeneity, potential endogeneity bias and volatility persistence, we find that firm-specific variation of stock returns in Turkey is only weakly correlated with alternative proxies of firm-specific variation in firm fundamentals and that the relationship is not robust to the influence of control variables such as the firm size. Our findings are, therefore, consistent with the usual perception that stock prices in emerging markets contain little firm-specific information.
\end{abstract}

Keywords: emerging markets, firm-specific variation in stock returns, firm-specific variation in fundamentals, panel data

JEL Classification: G 14, G18, G30, C33

\section{Introduction}

Some of the most commonly cited features that distinguish stock markets in emerging economies from the ones in well-developed economies include a higher average return, higher serial correlation, higher volatility, lower liquidity and low correlation with the developed stock markets (see, for example, Harvey, 1995; Bekaert and Harvey, 1997). Recently, Morck, Yeung and Yu (2000) draw our attention to yet another characteristic difference. They find that stock returns in developed markets tend to move in a relatively asynchronous pattern (i.e., show higher firm-specific variation), while in emerging markets, they tend to move in a relatively synchronous pattern (i.e., show lower firm-specific variation). Using data for 1995, they cannot justify the cross-country differences in firm-specific returns variation by alternative measures of firm-specific variation of stock fundamentals. Rather, they find that measures of institutional development such as good governance and stronger private property rights are significantly correlated with higher firm-specific returns variation. They suggest that poor institutions and weaker investor protections discourage informed investing in emerging markets and, therefore, stock prices in those economies contain little firm-specific information. These findings have important implications, because, for a stock market to be functionally efficient in directing capital resources to their most productive uses, it is a necessary condition that changes in stock prices track firm-specific fundamentals intimately (Tobin, 1984; Durnev, Morck, Yeung and Zarowin, 2003).

Interestingly, taking a time-series perspective, Li, Morck, Yang and Yeung (2004) report that firm-specific return variation in most of their seventeen sample emerging markets shows a rising pattern over the period from 1990 to 2000 . They find this pattern to be at least weakly similar to a rising trend of firm-specific return variation for the US stock market as documented in Campbell, Lettau, Malkiel and Xu (2001). In further analysis, Li et al. (2004) also show that the firm-specific variation in their sample markets is significantly positively correlated with greater capital market openness and institutional development over the period. They rationalize their 
findings by arguing that greater openness and good institutions may have induced greater firm-specific variation of stock returns in those markets by facilitating a better impounding of firm-specific information into stock prices.

More recent evidence presented in Chan and Hameed (2006) and Fernandes and Ferreira (2009), however, contradicts $\mathrm{Li}$ et al. (2004) position. Using firm-specific returns variation as a measure of the informativeness of stock prices, these two studies find either no, or even a negative, relationship between firm-specific returns variation in emerging markets and two specific measures of institutional development, namely, analysts' coverage and the enforcement of insider trading laws, respectively. While acknowledging the role of private information in driving firm-specific stock return variation, Roll (1988) also warns that higher firm-specific stock return variation may reflect a greater incidence of mispricing and noise trading as well. In this backdrop, it is essential that we understand the nature and the extent of the direct link between firm-specific variation of returns and firm fundamentals before interpreting the former as a gauge of the informativeness of stock prices in emerging markets.

In the wake of rising firm-specific returns variation in the US, a few studies have recently explored the link between firm-specific variations in returns and fundamentals in the US and reported a significant positive relationship both along the cross-sectional and time-series dimensions (Durnev et al., 2003; Wei and Zhang, 2006; Irvine and Pontiff, 2009). Similar cross-sectional evidence for Japan is also reported in Chang and Dong (2006). However, presumably due to limited availability of accounting data over a reasonable period of time, this issue has remained largely unexplored thus far in the context of individual emerging stock markets. Only recently, Rahman and Hassan (2012) examine the link between firm fundamentals and stock prices in the context of each of a set of emerging Asian markets. They find that there is a strong positive correspondence between stock prices and cash-flow proxies in Taiwan, Korea, Malaysia, India and Thailand, although the evidence is either very weak or nonexistent for firms in China, Indonesia, the Philippines and Pakistan. Consistent with their argument of potentially nontrivial institutional and other heterogeneities among these regional markets, they also find that the cash-flow sensitivity of stock prices is considerably higher for Taiwan and Korea than for other markets in the region. In this paper, we contribute to this line of emerging market research and investigate the correspondence between firm fundamentals and stock prices in the context of the Turkish stock market.

The stock market of Turkey provides a good case for the study because it is considered as one of the most open and advanced among the emerging stock markets in the Middle East and North Africa (MENA) region and beyond. Despite facing some persistent structural rigidities and untoward developments in its economic and political environments, the country has been through a relentless process of financial liberalization and institutional reforms over the last two decades aiming at freeing up the operation of its financial markets. Undoubtedly, in so far as the stock market is concerned, one of the key strategic thrusts of these liberalization and reform initiatives is to achieve a stock price mechanism that help direct capital resources to their best possible uses in the economy. As we have mentioned previously, a necessary condition to achieve such an efficient price mechanism is that the stock prices keep close track of firm-specific fundamental information. Whether this is indeed the case with the stock prices in Turkey is the issue we examine in this paper. Unfortunately, however, given the typical insufficiency of a long time-series of firm-level fundamentals data, it is very difficult to establish the true extent to which Turkish stock prices relate to fundamentals. Therefore, we adopt an efficient but relatively less data demanding panel data approach to test the statistical significance of the relationship in the cross-section of stocks. In pursuing our objective, we explore the relationship between firm-specific variations in stock returns and firm fundamentals in the framework of a simple present value relation, which posits that the changes in stock price reflects rational expectations about the present value of expected future cash-flows of the firm.

The rest of the paper is organized as follows: Section 2 provides an overview of development and realities of the Turkish stock market. Section 3 provides a description of the sample and firm-level data used in the study. Section 4 explains the framework of analysis and the construction of firm-specific measures of volatility of returns and fundamentals. Section 5 specifies the models and describes the estimation procedure. Section 6 presents and describes the empirical results. Section 7 summarizes and concludes the paper.

\section{Turkish Stock Market}

The financial system in Turkey was extremely bank-centered, highly repressive and strictly regulated one until the beginning of 1980 when a major liberalization and reform package sponsored by the World Bank and IMF was introduced. These reform initiatives seemed to have laid the basic foundations for freely functional financial markets by the end of the decade. Most important reform measures included deregulation of interest rates, 
removal of barriers to foreign investments, liberalization of the foreign exchange regime, development of regulatory structure and institutions for securities trading, establishment of the Istanbul Stock Exchange (ISE), and improvement of accounting, audit and disclosure standards for listed companies. Since its inception in 1986 with only 42 companies, ISE has grown significantly over time in terms of market capitalization, trading volume, foreign investor participation, product variety and sophistication and become one of the top emerging market exchanges of the world. By the end of 2007, the market capitalization of 319 listed stocks rose to approximately US $\$ 287$ billion, which was approximately 44.28 percent of Turkish GDP at the time. Annual turnover ratio (total value of shares traded during the year divided by the average market capitalization for the year) increased from approximately $20 \%$ in 1989 to approximately $135 \%$ in 2007 , with the highest value of nearly $243 \%$ achieved in 1995. Institutional participation and the number and variety of professionally managed funds in the market have also grown substantially over time.

A distinctive feature of the Turkish stock market is its openness. Foreign portfolio holding as a percentage of free-float market capitalization at ISE experienced a very rapid growth from around only 3\% in 1989 to as high as approximately $72 \%$ in 2007 , mainly due to the country's most liberal foreign exchange regime with a fully convertible currency. Turkey does not impose any restriction on foreign portfolio investors trading on its securities markets. Foreign individual and institutional investors can freely invest in securities and repatriate their proceeds with the help of eligible financial institutions.

Despite these positive developments with regard to its stock market, Turkey's progress in achieving a market driven economy with freely functioning financial markets has remained largely bumpy over the last two decades due mainly to its chronic macroeconomic imbalances. An ever rising public sector borrowing requirement, the issuance of government debt securities to meet fiscal deficits, high rates of interest on these securities and high inflation rates have prevented its stock market from delivering fully to private sector investment and production activities. In addition, its contribution to the deepening of overall financial sector of the economy has remained essentially unnoticeable over time. Although the proportion of bank deposits in total financial assets of Turkey has gradually declined in the post-liberalization period, the securities component of total financial assets is increasingly represented by government securities. Consequently, the share of private securities (comprising mainly corporate shares and bond) in the securities component of the nation's total financial assets has shrunk to only around 14\% in 2006 from around 34\% in 1989 (Capital Markets Board of Turkey, 2006).

Another likely factor limiting the size and growth of stock market in Turkey is a very concentrated ownership structure of the listed firms. Most of the firms tend to retain their family structure, typically making only about one-quarter of the equity publicly tradable when listed on ISE. The concern is that an open stock market lacking in depth and breadth may likely to be more vulnerable to any unexpected development in internal and external economic and political environments. The concentrated ownership structure of Turkish firms may also raise legitimate governance concerns relating to minority shareholder rights and corporate disclosures.

\section{Description of Data and Sample}

Our investigation of the relationship between firm fundamentals and stock prices depends on constructing variables from firm-level data on financial statement items as well as stock returns. We retrieve national currency denominated yearly accounting data for only non-financial firms listed on Istanbul Stock Exchange from Worldscope, which is accessible through Datastream ${ }^{\circledR}$. The sample covers a 14-year period from 1993 to 2006. In order to estimate firm-specific variation in stock fundamentals discussed later in the text, we require at least six years of consecutive financial statement data up to 2006 be available for a firm to be included in the panel of sample firms (Note 1). Although Turkey opened up its capital markets in August 1989 (Bekaert and Harvey, 2000), considering outright unavailability or sheer scarcity of accounting data for a meaningful number of firms from Worldscope, we choose 1993 as the beginning of our sample period. Following these criteria, we find only 19 firms at the beginning of our sample period, which grows to 138 by the end of the sample period.

In our analysis involving firm-specific variation in stock fundamentals, we focus on three separate cash flow measures for each firm: (i) sales per share (data item number 1505, SPS hereafter), (ii) earnings per share (data item number 254, EPS hereafter), and (iii) cash earnings per share, which is earnings per share adjusted for non-cash items like depreciation and amortization, (data item number 792, CEPS hereafter). We expect that these three measures together should sufficiently reflect any fundamental cash flow shocks affecting firms in the market.

We use weekly excess returns (Wednesday to Wednesday) to construct an annual measure of firm-specific returns volatility. This choice is driven by the competing needs for obtaining relatively higher frequency data for a better estimate of annual firm-specific returns volatility and, at the same time, avoiding possible microstructure 
noise. We collect weekly total return indices of individual stocks from Datastream ${ }^{\circledR}$. Average sight deposit rate collected from the central bank of Turkey is used as proxy risk-free rate. In addition, our overall analysis requires data on individual firms' market capitalization at weekly and annual frequencies and trading volume at annual frequency, which are also sourced from Datastream ${ }^{\circledR}$.

\section{Framework of Analysis and Construction of Variables}

In the context of the simple present value relation, a change in firm's stock price signals a change in one or both of the following: (i) the expected future cash flow, and (ii) the risk-adjusted discount rate. This formulation suggests that firm-specific returns variation should be the outcome of shocks to expected future cash-flow stream and/or shocks to discount rate. However, the source of firm-specific return variation not being a factor risk according to rational asset pricing models, it is unlikely that discount rate shocks would cause variation in firm-specific returns (see, for example, Irvine and Pontiff, 2009). Therefore, the present value relationship is assumed to suggest that firm-specific variation in returns is driven primarily by firm-specific cash-flow shocks. Our main variables of interest are constructed as follows.

\subsection{Firm-specific Returns Volatility}

In constructing our measure of firm-specific returns volatility, we use the Capital Asset Pricing Model (CAPM) to control for systematic risk of individual stock returns. Therefore, we run the following regression for each firm over each of its fiscal years using weekly excess returns

$$
r_{i, j}=\alpha+\beta \cdot r_{m, j}+\varepsilon_{i, j}
$$

where $r_{i, j}$ and $r_{m, j}$ are excess returns of firm $i$ and the market in week $j$, and $\varepsilon_{i, j}$ is firm-specific excess stock returns of firm $i$ in week $j$.

We require a firm to have at least 12 weekly observations in a year to estimate the regression in equation (1). Since the equation generates weekly firm specific excess returns, we obtain an annual measure of firm-specific returns volatility for firm $i$ during fiscal year $t, I V_{i, t}$, as follows

$$
I V_{i, t}=\sqrt{\sum_{j=1}^{J} \varepsilon_{i, j}^{2}}
$$

where $J$ is the number of weekly observations in the fiscal year $t$.

\subsection{Firm-specific Fundamentals Volatility}

We have already noted that we are using SPS, EPS and CEPS as alternative measures of cash flows. Since these variables usually exhibit strong persistence, we cannot interpret levels of them as incremental information about firm fundamentals. Therefore, we use the first-differences of our cash flow variables as the correct measure of shocks (incremental information) in each series. In addition, following Irvine and Pontiff (2009), we divide firm-level cash flow shock of year $t$ by the year-end stock price of year $t-1$. After computing firm-level cash flow shocks in this manner, we create an index of market-level cash flow shocks, which is simply a market capitalization weighted average of cash flow shocks across firms. Denoting the market cash flow shock index in year $t$ as $e_{m, t}$ and the cash flow shock of firm $i$ in year $t$ as $e_{i, t}$, we construct a time series of firm-specific variation in fundamentals based on the residuals from the following market-model type regression

$$
e_{i, t}=a+b \cdot e_{m, t}+u_{i, t}
$$

Specifically, as suggested by Schwert and Seguin (1990), we estimate firm-specific fundamentals volatility as

$$
C F I V_{i, t}=\left|\hat{u}_{i, t}\right| \sqrt{\pi / 2}
$$

where $\hat{u}_{i, t}$ is the estimated residual from equation (3). This definition of volatility is based on the result that

$$
E(|x|)=\sigma \sqrt{2 / \pi} \text { if } x \rightarrow N\left(0, \sigma^{2}\right) .
$$

It should be noted that the implementation of the above mentioned procedure may become quite problematic when fiscal years of firms vary widely in a market. Fortunately, all of our sample firms have 31 December of each year as their fiscal year end. A further cause of concern, however, is that firm-level accounting data may often be infested with outliers. Effect of such potentially misleading accounting numbers on regression results can be substantial, especially when we use relatively fewer observations. In order to mitigate this concern, we winsorize our accounting variables, viz., SPS, EPS, and CEPS. As the first step of the process, we transform each of the accounting variables by dividing their values by corresponding year-end stock prices. Then, if original 
value of the variable under consideration is greater (less) than the top $5^{\text {th }}$ (bottom $95^{\text {th }}$ ) percentile, we replace it by a value equal to the value of the observation at the top $5^{\text {th }}$ (bottom $95^{\text {th }}$ ) percentile. Finally, we re-transform the variable by multiplying by year-end stock prices.

\section{Model Specification and Estimation}

The main purpose of our study is to identify whether stock price movements in Turkey in the post-liberalization period contains significant information about changes in firm fundamentals. Accordingly, we analyze the effect of firm-specific cash-flow volatility on firm-specific returns volatility using the following dynamic specification.

$$
\ln I V_{i, t}=\alpha_{1} \ln I V_{i, t-1}+\alpha_{2} \ln C F I V_{i, t}+\delta_{t}+\eta_{i}+\varepsilon_{i, t}
$$

where $i$ is a firm, $t$ is a fiscal year, $\delta_{t}$ is a set of time-specific effects, $\eta_{i}$ is the full set of firm-specific effects which is time invariant within firms, and $\varepsilon_{i, t}$ is the random disturbance term. The lagged dependent variable, $\ln I V_{i, t-1}$, controls for any persistence in firm-specific returns volatility as documented in previous research (see for example, Jiang and Lee, 2006; Chang and Dong, 2006). Even though the coefficient on $\ln I V_{i, t-1}, \quad \alpha_{1}$, is not of direct interest for the purpose of our study, allowing for dynamics in the firm-specific volatility process ensures consistent estimates of other parameters (Bond, 2002). Our coefficient of interest is $\alpha_{2}$, which reflects whether firm-specific volatility of cash flow $(\ln C F I V)$ has any effect on firm-specific volatility of stock returns $(\ln I V)$.

Since $\ln I V_{i, t-1}$ is correlated with $\eta_{i}$ by construction in equation (5), ordinary least squares estimates lose their desirable properties of unbiasedness and consistency. Accordingly, our approach to estimating equation (5) follows Arellano and Bond (1991), Arellano and Bover (1995) and Blundell and Bond (1998). First, in order to remove firm-specific effects, $\eta_{i}$, we take first differences of equation (5) to obtain

$$
\Delta \ln I V_{i, t}=\alpha_{1} \Delta \ln I V_{i, t-1}+\alpha_{2} \Delta \ln C F I V_{i, t}+\Delta \delta_{t}+\Delta \varepsilon_{i, t}
$$

The above first-difference specification, however, although free from the firm-specific effects, generates an additional endogeneity issue because its $\ln I V_{i, t-1}$ term in $\Delta \ln I V_{i, t-1}$ correlates with the $\varepsilon_{i, t-1}$ term in $\Delta \varepsilon_{i, t}$. This problem along with the likely endogeneity of $\ln C F I V$ necessitates the use of instrumental variables in estimation (Note 2).

In order to address these problems, Arellano and Bond (1991) suggest a generalized method of moment technique that came to be known as the difference-GMM estimator. Assuming that the disturbances in equation (5) are serially uncorrelated and that the explanatory variables are uncorrelated with future realization of the disturbance term (Note 3), lags of $\ln C F I V$ and $\ln I V$ dated $t-2$ and earlier are valid instruments to identify the effect of exogenous variation in $\ln C F I V$ on $\ln I V$. Therefore, the difference-GMM estimator for equation (6) uses the following orthogonality conditions:

$$
E\left[\begin{array}{l}
\ln I V_{i, t-s} \Delta \varepsilon_{i, t} \\
\ln C F I V_{i, t-s} \Delta \varepsilon_{i, t}
\end{array}\right]=\left[\begin{array}{l}
0 \\
0
\end{array}\right] \quad \text { for } s \geq 2
$$

However, a problem with the difference estimator is that, when the time-series under investigation is highly persistent and the length of panels is short, the lagged levels of the variables are often rather poor instruments for the first differences of the series (Note 4). In addition, first-differencing may exacerbate the bias due to measurement error (as may be the case with our constructed volatility series) by increasing the variance of this error relative to the variance of the true signal (Griliches and Hausman, 1986).

To alleviate potential imprecision and biases associated with the usual difference-GMM estimator, we use an alternative and more efficient estimator - known as the system-GMM estimator. This estimator is suggested by Arellano and Bover (1995) and Blundell and Bond (1998). The system-GMM estimator uses lag differences of each variable as instruments in estimating the levels relationship in equation (5), and combines this information with the difference-GMM estimates of equation (6). The validity of these additional instruments requires that the first differences of the explanatory variables are not correlated with the firm-specific effect. Therefore, in the context our study, the additional orthogonality conditions for the equation in levels are

$$
E\left[\begin{array}{l}
\Delta \ln I V_{i, t-s}\left(\eta_{i}+\varepsilon_{i, t}\right) \\
\Delta \ln C F I V_{i, t-s}\left(\eta_{i}+\varepsilon_{i, t}\right)
\end{array}\right]=\left[\begin{array}{l}
0 \\
0
\end{array}\right] \quad \text { for } s \geq 1
$$


We check the validity of the conditions set forth in equation (7) and (8) under the null of orthogonality of instruments using the Hansen and the difference-in-Hansen test of overidentifying restrictions, respectively. Another critical assumption for the consistency of the system-GMM estimator is that there is no serial correlation in the disturbances in levels. If this assumption is correct, we would expect that the first-differenced disturbances of equation (6) to be significantly negatively autocorrelated at the first lag, but uncorrelated at the second lag. Therefore, we also test for the first-order and second-order serial correlation in the first-differenced disturbances under the null of no serial correlation.

Note that the orthogonality restrictions of equation (7) can generate many instruments since the length of lagged explanatory variables and disturbances can be as long as the individual firm observation length minus one (since disturbances are first-differenced). However, too many instruments can overfit endogenous variables and compromise computational efficiency (Judson and Owen, 1999). Hence, rather than using all available lags to instrument each variable, our main results are derived by using a restricted set of instruments. Specifically, instruments for the equation in first-differences are chosen based on the principle that the information in the lags of the regressors is tapped as much as possible until the valid lowest value of the Hansen statistic is obtained. On the other hand, instruments for the equation in levels are chosen to be lag-one first-differences of the regressors.

We also check whether the relationship between firm-specific variations in returns and fundamentals in Turkish stock market (based on equation 5) is robust to some control variables. This exercise is important, because there may exist other variables affecting firm-specific returns volatility which also relate to firm-specific fundamentals volatility. If we omit them from the analysis, the estimated coefficient on firm-specific fundamentals volatility variable could be biased. Our additional controls include firm trading volume, size, and leverage, which are frequently cited in the literature as having a significant effect on the volatility of stock returns. We use turnover ratio $\left(T R_{i, t}\right)$-the aggregate number of shares traded divided by the total number of shares outstanding for firm $i$ in fiscal year $t$ - as a measure of trading volume. Studies such as Wei and Zhang (2006) and Xu and Malkiel (2003) document that the larger firms tend to have smaller firm-specific returns volatility. Therefore, we use market capitalization of firms at the beginning of each fiscal year $\left(S I Z E_{i, t-1}\right)$ to control for potential size effect on firm-specific volatility of returns. Finally, following Chang and Dong (2006), we also include the lagged return $\left(R T N_{i, t-1}\right)$ as an additional control variable to account for the 'leverage effect' - the commonly observed negative relationship between stock returns and volatility. Therefore, we extend our basic model (equation 5) and estimate the following specification using the system-GMM procedure discussed earlier

$$
\ln I V_{i, t}=\alpha_{1} \ln I V_{i, t-1}+\alpha_{2} \ln C F I V_{i, t}+\alpha_{3} \ln T R_{i, t}+\alpha_{4} \ln S I Z E_{i, t-1}+\alpha_{5} R T N_{i, t-1}+\delta_{t}+\eta_{i}+\varepsilon_{i, t}
$$

\section{Analysis of Results}

Before producing results using our empirical models, a graphic presentation of our volatility measures at the aggregate level and some descriptive statistics of the variables used in the analysis may be instructive. Panel A, $\mathrm{B}$ and $\mathrm{C}$ of figure 1 plot the time series of equally weighted cross-sectional average of firm-specific stock returns volatility separately against equally weighted cross-sectional average of firm-specific fundamentals volatility in terms of SPS, EPS and CEPS, respectively. We observe that even though firm-specific returns volatility in Turkey shows a sharp declining pattern from about 0.35 in 1994 to about 0.20 in 1997, it remains largely stable over the rest of the sample period at around 0.20. Li et al. (2004) also report that firm-specific volatility in Turkey in the latter part of the 1990s was significantly lower than the earlier part of the decade. The episode of relatively higher level of firm-specific returns volatility earlier in our sample period also coincides with a rather bleak economic outlook of the Turkish economy. The country faced a severe currency crisis in 1994 and had to devalue Turkish lira by $65 \%$ against US dollar. Among the firm-specific fundamentals volatility measures, the one measured in terms of SPS - a rather crude measure of cash flow - maintains a high average level and shows less synchronous movements over time with the ones measured in terms of EPS and CEPS. Putting firm-specific volatility of returns vis-à-vis firm-specific fundamentals volatility, it is difficult to identify a clear general pattern of co-movement. However, our measures of cash flow volatility, particularly the ones based on EPS and CEPS, tend to move in the same direction as returns volatility during 1994 to 2001 period. 
Panel A

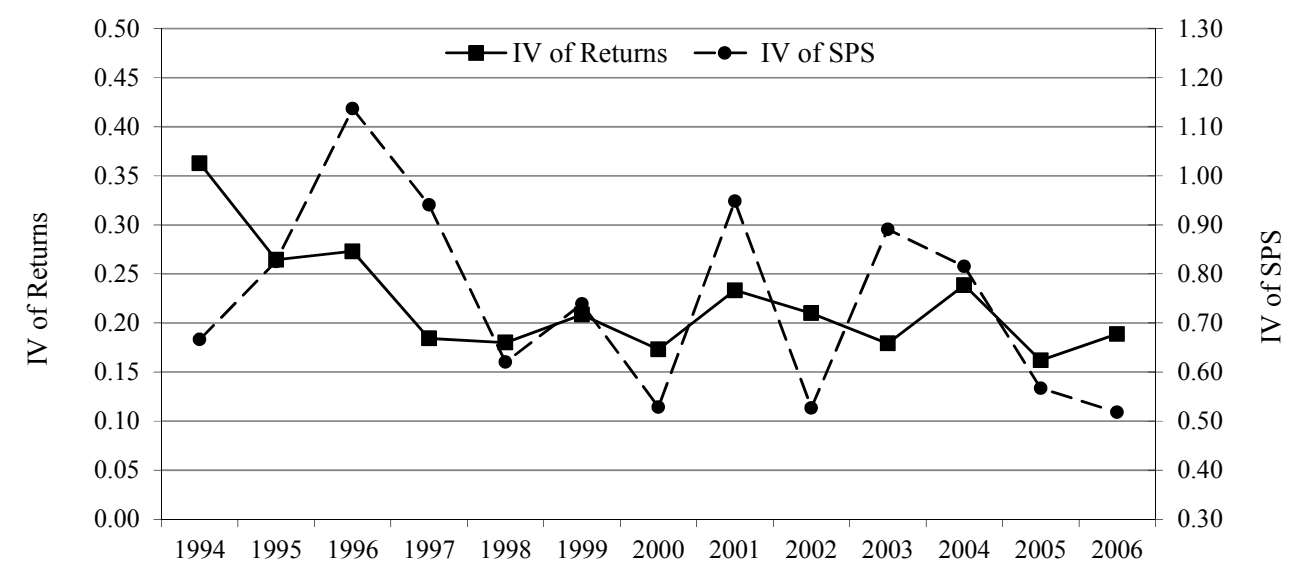

Panel B

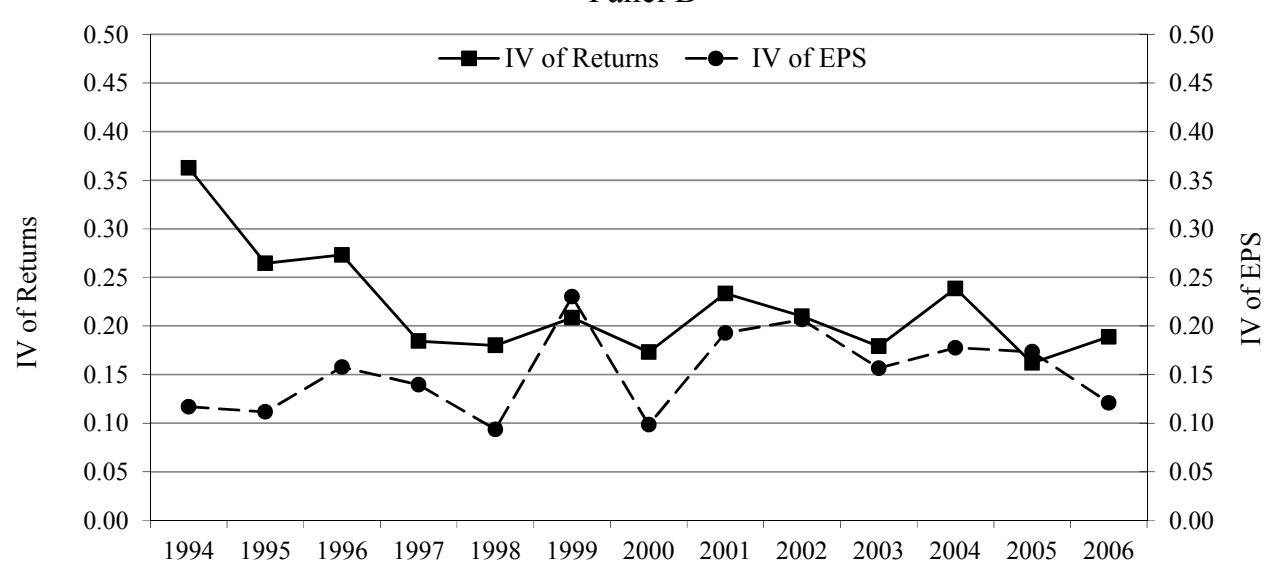

Panel C

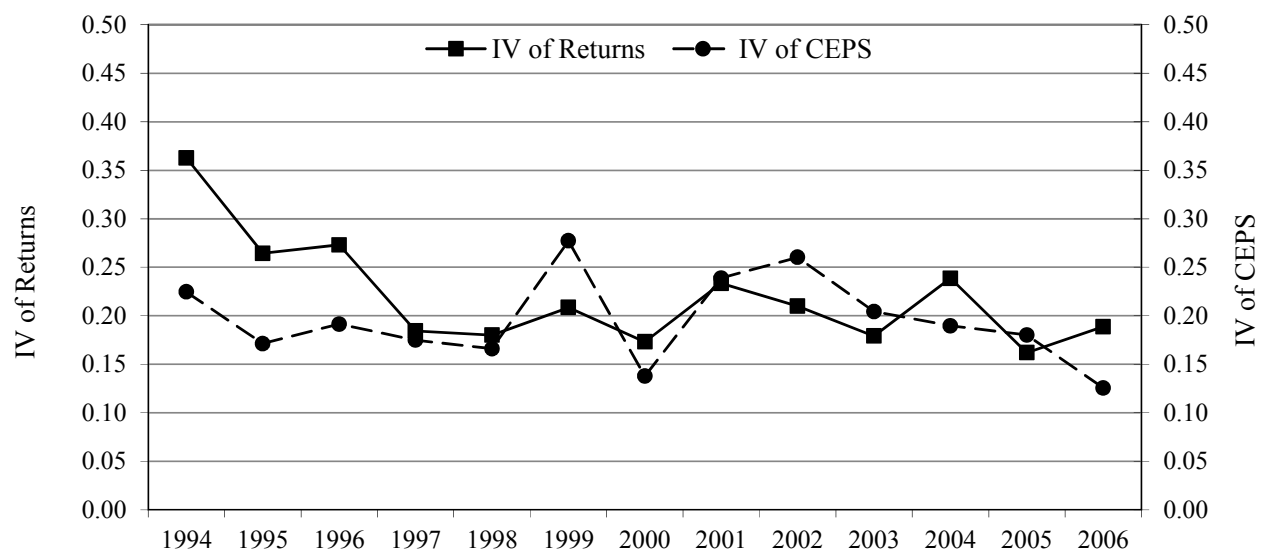

Figure 1. Yearly firm-specific variations in returns and fundamentals at the market level

Notes: Panel A, B and C of this figure plot market-level firm-specific variations of returns (IV of Returns) against firm-specific variations in each of the three proxies of cash flow- SPS, EPS and CEPS, respectively. The sample period is 1994 to 2006 and the equally weighted cross-sectional average for each year is used for all items. 
The descriptive statistics and correlation matrix of the variables used in the paper are presented in Panel A and B of Table 1, respectively. In Panel A, we see that firm-specific fundamentals volatility in terms of SPS has the highest average value and is most volatile compared to the ones measured in terms EPS and CEPS. Firm-specific volatility of returns shows remarkably lower variation across firms than the variation of any of the firm-specific fundamentals volatility measures. More importantly, the correlation matrix in Panel B of the table reveals that, while firm-specific returns volatility has very low but significant positive correlation with firm-specific EPS and CEPS volatility, its correlation with firm-specific SPS volatility is only insignificantly positive. Contrary to many previous findings, insignificant relationship of firm-specific returns volatility is also observed with average turnover ratio and lagged returns capturing the leverage effect in the market. However, consistent with the expectation, firm-specific returns volatility in Turkey has a strong negative correlation with the firm size. Although firm-specific volatility of cash flow variables correlate strongly positively with each other, correlation between volatility of EPS and CEPS has the highest value of all.

Table 1. Summary statistics of the variables used in the analysis

\begin{tabular}{|c|c|c|c|c|c|c|c|}
\hline \multicolumn{8}{|l|}{ Panel A: } \\
\hline & IV & $C F I V_{S P S}$ & $C F I V_{E P S}$ & $C F I V_{C E P S}$ & $T R$ & $\ln S I Z E$ & $R T N$ \\
\hline Mean & 0.1586 & 0.7082 & 0.1611 & 0.1962 & 2.5026 & 4.1127 & 0.3585 \\
\hline $25^{\text {th }}$ Percentile & 0.0752 & 0.1223 & 0.0311 & 0.0493 & 0.5344 & 2.8304 & -0.0689 \\
\hline $50^{\text {th }}$ Percentile & 0.1244 & 0.3305 & 0.0815 & 0.1051 & 1.3789 & 3.9659 & 0.2848 \\
\hline $75^{\text {th }}$ Percentile & 0.2056 & 0.7207 & 0.1800 & 0.2303 & 3.0852 & 5.2762 & 0.7156 \\
\hline Coef. of Variation & 0.8302 & 2.1554 & 1.6701 & 1.4864 & 1.3641 & 0.4262 & 1.8493 \\
\hline \multicolumn{8}{|l|}{ Panel B: } \\
\hline & $\ln I V$ & $\ln C F I V_{S P S}$ & $\ln C F I V_{E P S}$ & $\ln C F I V_{C E P S}$ & $\ln T R$ & $\ln S I Z E$ & $R T N$ \\
\hline $\ln I V$ & 1.0000 & & & & & & \\
\hline $\ln C F I V_{S P S}$ & $\begin{array}{c}0.0257 \\
{[0.380]}\end{array}$ & 1.0000 & & & & & \\
\hline $\ln C F I V_{E P S}$ & $\begin{array}{c}0.0658 \\
{[0.025]}\end{array}$ & $\begin{array}{c}0.2098 \\
{[0.000]}\end{array}$ & 1.0000 & & & & \\
\hline $\ln C F I V_{C E P S}$ & $\begin{array}{c}0.1321 \\
{[0.000]}\end{array}$ & $\begin{array}{c}0.2581 \\
{[0.000]}\end{array}$ & $\begin{array}{c}0.5167 \\
{[0.000]}\end{array}$ & 1.0000 & & & \\
\hline $\ln T R$ & $\begin{array}{c}-0.0256 \\
{[0.383]}\end{array}$ & $\begin{array}{c}0.1288 \\
{[0.000]}\end{array}$ & $\begin{array}{c}0.2603 \\
{[0.000]}\end{array}$ & $\begin{array}{c}0.2493 \\
{[0.000]}\end{array}$ & 1.0000 & & \\
\hline $\ln S I Z E$ & $\begin{array}{c}-0.3140 \\
{[0.000]}\end{array}$ & $\begin{array}{c}-0.1891 \\
{[0.000]}\end{array}$ & $\begin{array}{c}-0.2179 \\
{[0.000]}\end{array}$ & $\begin{array}{c}-0.2006 \\
{[0.000]}\end{array}$ & $\begin{array}{c}-0.1711 \\
{[0.000]}\end{array}$ & 1.0000 & \\
\hline$R T N$ & $\begin{array}{c}0.0216 \\
{[0.461]}\end{array}$ & $\begin{array}{c}-0.0952 \\
{[0.001]}\end{array}$ & $\begin{array}{c}-0.1580 \\
{[0.000]}\end{array}$ & $\begin{array}{c}-0.1352 \\
{[0.000]}\end{array}$ & $\begin{array}{c}-0.1186 \\
{[0.000]}\end{array}$ & $\begin{array}{c}0.0865 \\
{[0.003]}\end{array}$ & 1.0000 \\
\hline
\end{tabular}

Notes: Panel A of this Table presents descriptive statistics of the variables used in this paper. $I V$ represents firm-specific variation of stock returns. $C F I V_{S P S}, C F I V_{E P S}$ and $C F I V_{C E P S}$ denote measures of firm-specific variation of cash flows using sales per share (SPS), earnings per share (EPS) and cash earnings per share (CEPS), respectively. The control variables $T R, \ln S I Z E$ and $R T N$ represent annual turnover ratio, log of market capitalization and yearly stock returns of sample firms. Panel B presents the correlation matrix of the variables used, where all variables are log transformed except for stock returns. Figures in brackets are $p$-values of the corresponding correlation coefficients.

Table 2 presents the main results of our analysis based on the two-step system-GMM estimates of the baseline model (equation 5) and the extended model (equation 9). The response of firm-specific returns volatility in Turkey to changes in three separate measures of fundamentals volatility in terms of SPS, EPS and CEPS is reported, respectively, along Column 1,3 and 5 for the baseline model, and Column 2, 4 and 6 for the extended model. In all specifications, the lagged firm-specific returns volatility $\left(\ln I V_{i, t-1}\right)$ has positive coefficient with a minimum value of 0.1519 . Strong statistical significance of all the coefficients indicates that firm-specific returns volatility has some persistent feature. Examining the coefficients of firm-specific fundamentals volatility $\left(\ln C F I V_{i, t}\right)$ for the baseline model, we find that the coefficients of $\ln C F I V_{i, t}$ based on EPS and CEPS have expected positive and significant relationship with firm-specific returns volatility $\left(\ln I V_{i, t}\right)$ at the $10 \%$ and $5 \%$ 
level, respectively. On the other hand, $\ln C F I V_{i, t}$ based on SPS has a negative but insignificant association with $\ln I V_{i, t}$. We argue that the latter finding could have resulted for SPS being a very crude estimate of a firm's cash flow. More importantly, however, when we estimate the extended model, cash flow variables EPS and CEPS completely loose their significance to the effect of control variables, especially that of firm size $\left(\ln S I Z E_{i, t-1}\right)$. In conformity with the simple correlation analysis, $\ln S I Z E_{i, t-1}$ is the only control variable with which $\ln I V_{i, t}$ is found to have a strong negative relationship irrespective of the measure of cash flow volatility used in regression specifications.

Table 2. Relationship between firm-specific variations in returns and fundamentals

\begin{tabular}{ccccccc}
\hline & \multicolumn{2}{c}{$C F I V$ using SPS } & \multicolumn{2}{c}{$C F I V$ using EPS } & \multicolumn{2}{c}{$C F I V$ using CEPS } \\
\cline { 2 - 6 } $\operatorname{col}-1$ & Col.-2 & Col.-3 & Col.-4 & Col.-5 & Col.-6 \\
\hline \multirow{2}{*}{$\ln I_{i, t-1}$} & $0.1593^{*}$ & $0.1628^{*}$ & $0.1681^{*}$ & $0.1537^{*}$ & $0.1597^{*}$ & $0.1519^{*}$ \\
& {$[0.001]$} & {$[0.000]$} & {$[0.001]$} & {$[0.001]$} & {$[0.005]$} & {$[0.003]$} \\
$\ln C F I V_{i, t}$ & -0.0440 & -0.0310 & $0.1067^{* * *}$ & 0.0170 & $0.0973^{* *}$ & 0.0272 \\
& {$[0.395]$} & {$[0.521]$} & {$[0.065]$} & {$[0.710]$} & {$[0.028]$} & {$[0.415]$} \\
$\ln T R_{i, t}$ & & -0.0453 & & -0.0633 & & -0.0415 \\
& & {$[0.449]$} & & {$[0.264]$} & & {$[0.415]$} \\
$\ln S_{2 I Z E_{i, t-1}}$ & & $-0.2035^{*}$ & & $-0.1972^{*}$ & & $-0.1860^{*}$ \\
& & {$[0.000]$} & & {$[0.000]$} & & {$[0.000]$} \\
$R T N_{i, t-1}$ & & 0.0196 & & 0.0227 & & 0.0079 \\
Time effect & & {$[0.815]$} & & {$[0.755]$} & & {$[0.915]$} \\
\hline AR(1) & Yes & Yes & Yes & Yes & Yes & Yes \\
AR(2) & 0.000 & 0.000 & 0.000 & 0.000 & 0.000 & 0.000 \\
Hansen & 0.208 & 0.223 & 0.332 & 0.320 & 0.147 & 0.255 \\
Diff- Hansen & 0.196 & 0.348 & 0.158 & 0.645 & 0.192 & 0.662 \\
Instruments & 0.536 & 0.224 & 0.657 & 0.495 & 0.608 & 0.729 \\
Firms & 85 & 121 & 102 & 131 & 93 & 121 \\
Firm-years & 138 & 138 & 138 & 138 & 138 & 138 \\
\hline & 1026 & 1026 & 1026 & 1026 & 1026 & 1026 \\
\hline
\end{tabular}

Notes: This Table reports the results of the two-step System-GMM estimation of the relationship between log of firm-specific variations in returns $(\ln I V)$ and cash flows $(\ln C F I V)$. While Column 1, 3 and 5 of the table report results of estimating our baseline model specified in equation (5), Column 2, 4 and 6 report the results based on our extended model specified in equation (9) using sales per share (SPS), earnings per share (EPS) and cash earnings per share (CEPS) respectively as alternative cash flow proxies. In the extended model, we use log of turnover ratio $\left(\ln T R_{i, t}\right), \log$ value of firm size $\left(\ln S I Z E_{i, t-1}\right)$ and leverage effect $\left(R T N_{i, t-1}\right)$ to capture potential effects these variables on the relationship. Figures in brackets are $p$-values based on Windmeijer (2005) corrected standard errors. $\operatorname{AR}(k)$ are the $p$-values for the test of $k$-th order autocorrelation in the first-differenced residuals. The values reported for the Hansen test are the $p$-values for the null hypothesis of instrument validity. The Diff-Hansen reports the $p$-values for the validity of the additional moment restrictions required by the System-GMM. Statistical significance of the coefficients at $1 \%, 5 \%$, and $10 \%$ level is indicated by *,**, and ***, respectively.

Given the overwhelming effect of firm size on our regression results, it might be rather tempting to examine if and how the relationship between firm-specific volatility of returns and fundamentals in Turkey would change with the firm size. In the context of an emerging market like Turkey, the implications of firm size for the relationship between firm-specific variations in returns and fundamentals is not clear. Previous studies have found that firm size is positively associated with the level of institutional ownership since institutional investors have a preference for liquid assets. Greater institutional ownership and activities of institutional investors have the effect of increasing the amount of firm-specific information that is incorporated into stock prices $(\mathrm{Xu}$ and Malkiel, 2003; Chang and Dong, 2006). On the other hand, however, as in most other emerging markets, many of the larger firms in Turkey form part of some family owned business groups. Corporate governance concerns surrounding those business groups, such as the possibility of inter-firm income and wealth transfers, may discourage informed risk arbitrage based on available firm-specific information in the market. To see how cash flow sensitivity of firm-specific returns volatility vary with the firm size, we estimate equation (9) by including an interaction term of $\ln C F I V_{i, t}$ and $\ln \operatorname{SIZE}_{i, t-1}$ (Note 5). Considering the previously observed poor explanatory power of $\ln T R_{i, t}$ and $R T N_{i, t-1}$, we drop them from this analysis. Results are reported in Table 3. A general 
insignificance of the interaction term across cash flow proxies clearly suggests that there is no size dependence of the relationship between firm-specific variations in returns and fundamentals in Turkey. Alongside these results, however, the previously observed insignificance of $\ln C F I V_{i, t}$ and strong significance of $\ln S I Z E_{i, t-1}$ in driving $\ln I V_{i, t}$ continue to hold in this table.

Table 3. Size dependence of the relationship between firm-specific variations in returns and fundamentals

\begin{tabular}{cccc}
\hline & \multicolumn{3}{c}{ Proxies of Cash Flow } \\
\cline { 2 - 4 } & SPS & EPS & CEPS \\
\hline $\ln I V_{i, t-1}$ & $0.1709^{*}$ & $0.1951^{*}$ & $0.1694^{*}$ \\
$\ln C F I V_{i, t}$ & {$[0.000]$} & {$[0.000]$} & {$[0.000]$} \\
& -0.0424 & -0.0674 & 0.0482 \\
$\ln C F I V_{i, t} \times \ln S I Z E_{i, t-1}$ & $0.719]$ & {$[0.459]$} & {$[0.630]$} \\
& {$[0.580]$} & {$[0.582]$} & -0.0152 \\
$\ln S I Z E_{i, t-1}$ & $-0.1491^{*}$ & $-0.1440^{* *}$ & $-0.1835^{*}$ \\
& {$[0.007]$} & {$[0.053]$} & {$[0.008]$} \\
Time effect & Yes & Yes & Yes \\
\hline AR $(1)$ & 0.000 & 0.000 & 0.000 \\
AR(2) & 0.289 & 0.175 & 0.232 \\
Hansen & 0.361 & 0.691 & 0.574 \\
Diff- Hansen & 0.524 & 0.787 & 0.866 \\
Instruments & 120 & 120 & 120 \\
Firms & 138 & 138 & 138 \\
Firm-years & 1026 & 1026 & 1026 \\
\hline
\end{tabular}

Notes: This Table reports the results of testing the size dependence of the relationship between log of firm-specific variations in returns $(\ln I V)$ and cash flows $(\ln C F I V)$ using the two-step System-GMM procedure. $\ln S I Z E_{i, t-1}$ is log value of firm size. CFIV is measured in terms of sales per share (SPS), earnings per share (EPS) and cash earnings per share (CEPS), respectively. Figures in brackets are $p$-values based on Windmeijer (2005) corrected standard errors. AR $(k)$ are the $p$-values for the test of $k$-th order autocorrelation in the first-differenced residuals. The values reported for the Hansen test are the $p$-values for the null hypothesis of instrument validity. The Diff-Hansen reports the $p$-values for the validity of the additional moment restrictions required by the System-GMM. Statistical significance of the coefficients at $1 \%$ and $5 \%$ level is indicated by $*$ and $* *$, respectively.

The reliability of the regression results presented in the paper depends critically on the validity of the specifications used. Therefore, we append some important diagnostic test results towards the end of both Table 2 and 3. The $p$-values of the AR(1) and AR(2) in both tables testify the presence of first order and the absence of second order autocorrelation in the residuals of the equation in first-differences. In addition, the general insignificance of the Hansen and the difference-in-Hansen test of overidentifying restrictions provide evidence for the validity of the full set of instruments and the subset of additional instruments for the system-GMM estimators, respectively. We also report instrument count for each regression, which never exceeds the number of cross-sections and is generally around 10 percent of the number of firm-year observations.

\section{Conclusion}

A growing literature in finance relates firm-specific volatility of stock returns to variables that, in one way or another, are proxies of the information content of stock prices. Since emerging stock markets, unlike their well-developed counterpart, tend to show low firm-specific stock return variation relative to total return variation, it is generally perceived that changes in stock prices in these markets do not reflect sufficient firm-specific information. Li et al. (2004), however, suggest that greater capital market openness and associated market reforms during 1990s have induced higher firm-specific returns variation in majority of the emerging stock markets. They argue that greater openness and good institutions facilitates better impounding of firm-specific information into stock prices, which in turn translates into higher firm-specific variation of stock returns in those markets.

Since its liberalization in 1989, the Turkish stock market is considered as the one of the most liberal emerging stock markets in the world. In this paper, we look at the pattern of firm-specific returns variation in the 
post-liberalization period, and analyze it to assess whether the changes in stock prices in Turkey reflect sufficient information about the changes in firm fundamentals. We do so in the context of a simple present value framework and examine the relationship between firm-specific variations in returns and fundamentals, where the latter is measured in terms of three different proxies, viz., SPS, EPS and CEPS.

Contrary to the common experience of many other emerging markets, we observe that Turkish market liberalization and other reform initiatives seem to have failed to induce an increasing trend in firm-specific returns variation at the market level. Our regression results show that, although firm-specific variation in fundamentals measured in terms of EPS and CEPS exerts significant influence on firm-specific returns variation in Turkey, the effect is not robust to the influence of some other variables known for their relationship with return volatility, viz., firm size, trading volume and leverage. Specifically, our initial finding of the significance of variation in firm fundamentals seems to be driven indirectly by the characteristics of firms as represented by their size in particular. In order to understand the implications of the overwhelming effect of firm size more clearly, we examine whether the relationship between firm-specific variation in returns and fundamentals in Turkey vary with the firm size. However, we do not find any evidence of size dependence of the relationship either.

In summary, therefore, the results presented in this paper are not in line with what Li et al. (2004) suggest one to expect of an open and institutionally well-developed emerging stock market like Turkey. Rather, they are more aligned with the conventional view that the changes in stock prices in emerging markets do not reflect significant amount information about firm fundamentals. Although we do not directly model the effect of openness and institutional reforms in this study, our findings also indirectly cast doubts on the effectiveness of Turkish liberalization and reform initiatives in improving the information environment of its stock market; at least over the period covered under the study.

\section{References}

Arellano, M., \& Bond, S. (1991). Some tests of specification for panel data: Monte Carlo evidence and an application to employment equations. Review of Economic Studies, 58, 277-297. http://dx.doi.org/10.2307/2297968

Arellano, M., \& Bover, O. (1995). Another look at the instrumental variable estimation of error-component models. Journal of Econometrics, 68, 29-51. http://dx.doi.org/10.1016/0304-4076(94)01642-D

Bekaert, G., \& Harvey, C. R. (1997). Emerging equity market volatility. Journal of Financial Economics, 43, 29-78. http://dx.doi.org/10.1016/S0304-405X(96)00889-6

Bekaert, G., \& Harvey, C. R. (2000). Foreign speculators and emerging equity markets. Journal of Finance, 55, 565-614. http://dx.doi.org/10.1111/0022-1082.00220

Blundell, R., \& Bond, S. (1998). Initial conditions and moment restrictions in dynamic panel data models. Journal of Econometrics, 87, 115-143. http://dx.doi.org/10.1016/S0304-4076(98)00009-8

Bond, S. (2002). Dynamic panel data models: A guide to micro data methods and practice. Portuguese Economic Journal, 1, 141-162. http://dx.doi.org/10.1007/s10258-002-0009-9

Campbell, J. Y., Lettau, M., Malkiel, B. G., \& Xu, Y. (2001). Have individual stocks become more volatile? An empirical exploration of idiosyncratic risk. Journal of Finance, 56, 1-43. http://dx.doi.org/10.1111/0022-1082.00318

Capital Markets Board of Turkey. (2006). Annual Report 2006, Capital Markets Board of Turkey, Ankara.

Chan, K., \& Hameed, A. (2006). Stock price synchronicity and analyst coverage in emerging markets. Journal of Financial Economics, 80, 115-147. http://dx.doi.org/10.1016/j.jfineco.2005.03.010

Chang, E. C., \& Dong, S. (2006). Idiosyncratic volatility, fundamentals, and institutional herding: Evidence from the Japanese stock market. Pacific-Basin Finance Journal, 14, 135-154. http://dx.doi.org/10.1016/j.pacfin.2005.09.001

Durnev, A., Morck, R., Yeung, B., \& Zarowin, P. (2003). Does greater firm-specific return variation mean more or less informed stock pricing?. Journal of Accounting Research, 41, 797-836. http://dx.doi.org/10.1046/j.1475-679X.2003.00124.x

Durnev, A., Morck, R., \& Yeung, B. (2004). Value-enhancing capital budgeting and firm-specific stock return variation. Journal of Finance, 59, 65-105. http://dx.doi.org/10.1111/j.1540-6261.2004.00627.x

Fernandes, N., \& Ferreira, M. A. (2009). Insider trading laws and stock price informativeness. Review of 
Financial Studies, 22, 1845-1887. http://dx.doi.org/10.1093/rfs/hhn066

Griliches, Z., \& Hausman, J. (1986). Errors in variables in panel data. Journal of Econometrics, 31, 93-118. http://dx.doi.org/10.1016/0304-4076(86)90058-8

Harvey, C. R. (1995). Predictable risk and returns in emerging markets. Review of Financial Studies, 8, 773-816. http://dx.doi.org/10.1093/rfs/8.3.773

Irvine, P. J., \& Pontiff, J. (2009). Idiosyncratic return volatility, cash flows, and product market competition. Review of Financial Studies, 22, 1149-1177. http://dx.doi.org/10.1093/rfs/hhn039

Jiang, X., \& Lee, B-S. (2006). The dynamic relation between returns and idiosyncratic volatility. Financial Management, 35, 43-65. http://dx.doi.org/10.1111/j.1755-053X.2006.tb00141.x

Judson, R. A., \& Owen, A. L. (1999). Estimating dynamic panel data models a guide for macroeconomists. Economics Letters, 65, 9-15. http://dx.doi.org/10.1016/S0165-1765(99)00130-5

Li, K., Morck, R., Yang, F., \& Yeung, B. (2004). Firm-specific variation and openness in emerging markets. Review of Economics and Statistics, 86, 658-669. http://dx.doi.org/10.1162/0034653041811789

Morck, R., Yeung, B., \& Yu, W. (2000). The information content of stock markets: Why do emerging markets have synchronous price movements?. Journal of Financial Economics, 58, 215-260. http://dx.doi.org/10.1016/S0304-405X(00)00071-4

Pagan, A. R. (1984). Econometric issues in the analysis of regressions with generated regressors. International Economic Review, 25, 221-247. http://dx.doi.org/10.2307/2648877

Pagan, A. R., \& Ullah, A. (1988). The econometric analysis of models with risk terms. Journal of Applied Econometrics, 3, 87-105. http://dx.doi.org/10.1002/jae.3950030202

Rahman, M. A., \& Hassan, M. K. (2012). Firm fundamentals and stock prices in emerging Asian stock markets: some panel data evidence. Quantitative Review of Finance and Accounting. http://dx.doi.org/10.1007/s11156-012-0316-x

Roll, R. (1988). R . Journal of Finance, 43, 541-566. http://dx.doi.org/10.1111/j.1540-6261.1988.tb04591.x

Schwert, G. W., \& P. J. Seguin. (1990). Heteroskedasticity in stock returns. Journal of Finance, 45, 1129-1156. http://dx.doi.org/10.1111/j.1540-6261.1990.tb02430.x

Tobin, J. (1984). On the efficiency of the financial system. Fred Hirsch Memorial Lecture, New York, Lloyds Bank Review, 153, 1-15.

Wei, S. X., \& Zhang, C. (2006). Why did individual stocks become more volatile?. Journal of Business, 79, 259-292. http://dx.doi.org/10.1086/497411

Windmeijer, F. (2005). A finite sample correction for the variance of linear efficient two-step GMM estimators. Journal of Econometrics, 126, 25-51. http://dx.doi.org/10.1016/j.jeconom.2004.02.005

Xu, Y., \& Malkiel, B. G. (2003). Investigating the behavior of idiosyncratic volatility. Journal of Business, 76 , 613-644. http://dx.doi.org/10.1086/377033

\section{Notes}

Note 1. As is discussed in sub-section 4.2 of the paper, we lose the first annual observation for each firm in estimating firm-specific variation in fundamentals and, therefore, use at least five years of accounting data in estimation. While we acknowledge that using more years of data arguably adds to the precision of estimates, given the scarcity of accounting data for emerging market firms, it worsens the problem of obtaining data for a statistically meaningful number of firms. Due to similar reasons, Morck et al. (2000), Yeung and Yu (2000) and Durnev, Morck and Yeung (2004) use, respectively, at least five and six years of accounting data in estimating their firm-specific fundamentals variation.

Note 2. $\ln C F I V$ may be endogenous in the sense that it is not unlikely to be associated with firm-specific characteristics. Alternatively, there may exist a common cause for firm-specific returns and fundamentals volatility. In addition, measurement errors in $\ln C F I V$ may also serve as a source of endogeneity. Pagan (1984) and Pagan and Ullah (1988) also suggest using instrumental variables to reduce measurement errors associated with constructed measures of volatility.

Note 3. Endogeneity of explanatory variables implies that the variables are correlated with current values of the disturbances. 
Note 4. A simple transformation of an $\operatorname{AR}(1)$ process to $\Delta y_{i, t}=(\beta-1) y_{i, t-1}+\varepsilon_{i, t}$ helps us visualize the week instrument argument. Here, the higher the persistence, $\beta$, the lower the $E\left(y_{i, t-1} \Delta y_{i, t}\right)$.

Note 5. An alternative way to examine whether the firm size affects the sensitivity of stock returns variation to cash flow shocks would be to study the relationship between firm-specific variations in returns and fundamentals on different size-sorted portfolios of firms. Given a relatively small number of firms in our sample, we follow this procedure. 